\title{
A confusing case of canine vector-borne disease: clinical signs and progression in a dog co-infected with Ehrlichia canis and Bartonella vinsonii ssp. berkhoffii
} Edward B Breitschwerdt*, Ricardo G Maggi

\author{
Address: Department of Clinical Sciences, College of Veterinary Medicine, North Carolina State University, 4700 Hillsborough Street, Raleigh, \\ NC 27606, USA \\ Email: Edward B Breitschwerdt* - ed_breitschwerdt@ncsu.edu
}

${ }^{*}$ Corresponding Author

from 4th International Canine Vector-Borne Disease Symposium Seville, Spain. 26-28 March 2009

Published: 26 March 2009

Parasites \& Vectors 2009, 2(Suppl I):S3 doi:10.1 I86/I756-3305-2-SI-S3

This article is available from: http://www.parasitesandvectors.com/content/2/SI/S3

(C) 2009 Breitschwerdt and Maggi; licensee BioMed Central Ltd.

This is an Open Access article distributed under the terms of the Creative Commons Attribution License (http://creativecommons.org/licenses/by/2.0), which permits unrestricted use, distribution, and reproduction in any medium, provided the original work is properly cited.

\begin{abstract}
Bartonella spp. are important pathogens in human and veterinary medicine, and bartonellosis is considered as an emerging zoonosis that is being reported with increasing frequency. Of 22 known species and subspecies of Bartonella, seven have been isolated from dogs, causing disease manifestations similar to those seen in human beings. The wide variety of clinical signs and the possible chronic progression of disease manifestations are illustrated in the case of an infected Labrador retriever. Here, the authors discuss the seemingly diverse spectrum of disease manifestations, the co-infections of Bartonella spp. with other vector-borne pathogens (mainly Ehrlichia spp. or Babesia spp.) and the difficulties in microbiological confirmation of an active Bartonella infection, all of which make the disease pathogenesis and clinical diagnosis more problematic.
\end{abstract}

\section{Findings}

Historically, the most prevalent Bartonella species in dogs, B. vinsonii ssp. berkhoffii, was initially isolated from a dog with endocarditis and intermittent epistaxis in $1993[1,2]$. Subsequently, this pathogen has also been associated with cardiac arrhythmias, myocarditis, granulomatous rhinitis, anterior uveitis and chorioditis [1,3-6]. Other Bartonella species which have also been associated with pathology and clinical signs in dogs, including endocarditis, hepatic disease and sudden death are: B. henselae [7-11],
B. clarridgeiae $[9,12]$, B. washoensis [13], B. elizabethae [14] and $B$. quintana [15]. The first and the last, $B$. henselae and $B$. quintana, were also detected in the blood or lymph nodes of healthy dogs and dogs suffering from lymphoma [8]. More recent studies indicate that $B$. henselae may be the most frequent cause of bartonellosis in dogs.

The numerous disease manifestations in dogs, many of which are similar to those seen in humans, are listed in Table 1. 
Table I - Bartonella infection in dogs.

\begin{tabular}{|c|c|}
\hline Species/subspecies & $\begin{array}{l}\text { Associated manifestations } \\
\text { of infection [23-3I] }\end{array}$ \\
\hline \multirow[t]{9}{*}{ Bartonella vinsonii subsp. berkhoffii } & Endocarditis* \\
\hline & Cardiac arrhythmias* \\
\hline & Myocarditis* \\
\hline & Polyarthritis* \\
\hline & Granulomatous rhinitis \\
\hline & Anterior uveitis \\
\hline & Chorioretinitis* \\
\hline & Meningoencephalitis* \\
\hline & Anaemia/Thrombocytopenia* \\
\hline \multirow[t]{8}{*}{ Bartonella henselae } & Peliosis hepatitis* \\
\hline & Granulomatous hepatitis* \\
\hline & Generalised pyogranulomatous \\
\hline & lymphadenitis* \\
\hline & Panniculitis \\
\hline & Endocarditis* \\
\hline & Polyarthritis* \\
\hline & Idiopathic effusions \\
\hline Other Bartonella species & Endocarditis* \\
\hline Bartonella clarridgeiae & Hepatic disease \\
\hline B. washoensis & Weight loss \\
\hline \multicolumn{2}{|l|}{ B. elizabethae } \\
\hline B. quintana & \\
\hline
\end{tabular}

* Denotes disease manifestations reported in dogs and human beings.

Bartonella spp. are transmitted by bites and scratches of infected animals to other hosts. In addition, arthropod vectors may play the most important role in the transmission of these organisms. B. henselae, the agent of cat-scratch disease (CSD), has been isolated from cat fleas, and transmission by ticks has been proposed $[16,17]$. Although tick transmission of B. vinsonii ssp. berkhoffii has been suspected for over a decade based upon epidemiological evidence, this has not been proven [17]. Evidence suggests that dogs, coyotes and gray foxes may be the reservoir hosts for $B$. vinsonii ssp. berkhoffii $[18,19]$. Due to the mode of transmission a co-infection with other arthropod-borne pathogens is possible and may mask or alter the typical clinical signs of each of these pathogens. The following case of a chronically ill Labrador retriever is shortly outlined to illustrate the potential confusion and clinical challenges induced by tick-borne infections:

A 3-year-old, spayed, female Labrador retriever was referred to the North Carolina State University Veterinary Teaching Hospital for evaluation of a protracted illness that had begun approximately 9 months earlier. Initially, the dog was lethargic and intermittently inappetent and had a shifting-leg lameness suggestive of polyarthritis. On the initial examination prior to referral, the dog was mildly anaemic (haematocrit, 36\%) and hyperproteinaemic $(8.0 \mathrm{~g} / \mathrm{dl})$, but showed no obvious physical exami- nation abnormalities. Two weeks later, the dog developed a grand mal seizure, accompanied by spontaneous urination. During the subsequent month, lethargy continued and weight loss was recorded $(5.0 \mathrm{~kg})$. On a second veterinary examination numerous intradermal haemorrhages on the neck and trunk were noticed as well as anaemia (haematocrit: $32 \%$ ) with spherocytosis, mild thrombocytopenia (platelets: 180,000/ $\mu \mathrm{l}$ ), hyperglobulinaemia (serum globulin concentration: $4.7 \mathrm{~g} / \mathrm{dl}$ ), proteinuria, and hemoglobinuria (urine specific gravity: $1.034 ; 4+$ protein; $4+$ blood; 4 to 8 erythrocytes per highpower field) and physiological leukocyte counts and differential cell numbers. Seroreactivity to Ehrlichia canis, Rickettsia rickettsii and nuclear (antinuclear antibodies) antigens by indirect fluorescent-antibody assays (reciprocal titers, 50, 256 and 640, respectively) were detected. Ehrlichiosis and systemic lupus erythematosus were diagnosed by the referring veterinarian.

Treatment was initiated with tetracycline hydrochloride (750 mg 3 times daily for 14 days) and prednisone (40 mg twice daily (BID) for 3 days, then gradually tapered to $15 \mathrm{mg}$ every other day).

During the next 3 months, episodes of listlessness and epistaxis occurred and on referral examination the dog was lethargic with slight tachycardia, a hyperdynamic arterial pulse accompanied by arterial pulse deficits and occasional premature beats. A diastolic and a systolic heart murmur were recorded. On electrocardiogram and spectral Doppler echocardiography extrasystoles and severe aortic as well as mild mitral valve insufficiency were diagnosed, already resulting an increase in interstitial and alveolar pulmonary infiltrates in the accessory lung lobe (thoracic radiographs). Laboratory parameters proved anaemia (haematocrit: 33\%; mild anisocytosis and macrocytosis), thrombocytopenia (platelet count: $121,000 / \mu \mathrm{l}$ ), leukocyte counts at 12,300/ $\mu \mathrm{l}$, with normal differential cell numbers, hypoalbuminaemia (serum albumin: $2.6 \mathrm{~g} / \mathrm{dl}$ ), azotaemia (blood urea nitrogen: $34 \mathrm{mg} / \mathrm{dl}$ ) and hypokalaemia (serum potassium: $3.9 \mathrm{~g} / \mathrm{dl}$ ). Urinalysis again revealed proteinuria and haemoglobinuria (specific gravity: $1.011 ; 3+$ protein; $2+$ blood), haematuria (5 to 10 erythrocytes per high-power field), pyuria (5 to 10 leukocytes per high-power field) and bacteriuria. Aerobic and anaerobic blood cultures during a 24-h period as well as terminal subcultures and Gram stains performed after 7 days failed to grow or identify bacteria. Blood cultured simultaneously by the lysis centrifugation technique grew a fastidious, gramnegative organism. Seroreactivity (indirect fluorescentantibody assay) to $E$. canis and $R$. rickettsii was again positive (reciprocal titers, 64 and 128, respectively) and a specific antibody response to E. canis was confirmed by Western immunoblot analysis. 
Treatment for bacterial endocarditis accompanied by congestive heart failure consisted of enrofloxacin (306 mg BID), doxycycline (400 mg BID), clavulanate-potentiated amoxicillin (530 mg BID), furosemide (40 mg BID), digoxin (0.25 mg BID) and enalapril (20 mg BID). But because of a lack of substantial clinical improvement, intractable epistaxis and the poor long-term prognosis associated with vegetative valvular endocarditis, the owners elected euthanasia 17 days following discharge.

A lysis centrifugation technique finally isolated $B$. vinsonii ssp. berkhoffii genotype I in this dog by blood culture so that it was suggested that the dog was co-infected with E. canis and B. vinsonii ssp. berkhoffii. Reactivity to Rickettsia antigens is suggested to be cross-reactive with Bartonella antigens and anti-nuclear antibodies can occur with an increased frequency in dogs that are seroreactive to B. vinsonii ssp. berkhoffii and E. canis antigens [20].

The above-described case report highlights three problems related to infections with Bartonella spp.: (1) A large variety of disease manifestations makes a clinical diagnosis more difficult (diagnostic indications that support the testing for Bartonella infection are listed in Table 2); (2) co-infections of Bartonella spp. with other vector-borne pathogens particularly Ehrlichia spp. or Babesia spp. may influence the pathogenesis of those diseases and alternatively co-infection may also alter clinical signs of bartonellosis, creating substantial challenges for the clinician in regard to accurate diagnosis and directed medical management; (3) microbiological confirmation of an active Bartonella infection is difficult. Concerning the last point, and as is seen with other intracellular pathogens that induce chronic infection after vector-borne transmission, this aspect of diagnostic confirmation can be very challenging [7]. Ideally, diagnosis should be confirmed by culturing the organism from biopsy specimens, blood or fluid samples that are aseptically obtained. Due to the fastidious growth characteristics of Bartonella spp. it is important to avoid contamination of diagnostic specimens with skin flora or other rapidly growing bacteria. Unlike cats, which may

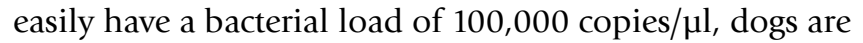
likely to have levels that are 100- to 1000 -fold lower [7]. The presence of antibodies can only be used to infer prior exposure, but a substantial number of infected dogs do not have detectable antibodies. PCR amplification of Bartonella DNA following direct extraction from patient samples is also relatively insensitive. Two media have been developed to overcome the problem of slow-growing pathogens and unavailable liquid medium: "BAPGM" medium [21] and another medium developed by Riess et al. [22]. Nevertheless, culturing remains very timeconsuming and when the need for a diagnosis is urgent, treatment should be started after obtaining appropriate
Table 2 - Differential diagnostic indications that support consideration of testing for Bartonella infection.

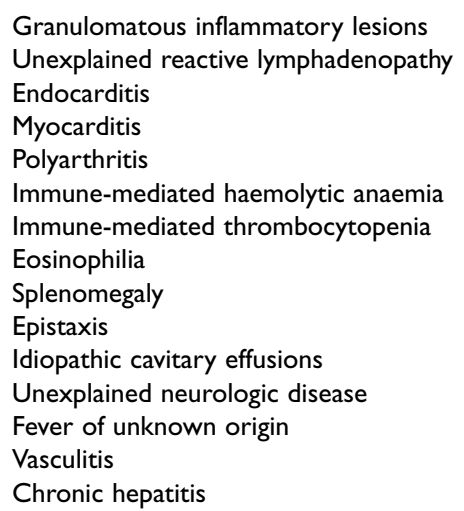

Granulomatous inflammatory lesions

Unexplained reactive lymphadenopathy

Endocarditis

Myocarditis

Polyarthritis

Immune-mediated haemolytic anaemia

Immune-mediated thrombocytopenia

Eosinophilia

Splenomegaly

Epistaxis

Idiopathic cavitary effusions

Unexplained neurologic disease

Fever of unknown origin

Vasculitis

Chronic hepatitis

diagnostic specimens. Serum antibodies can be detected in both healthy and clinically ill dogs and thus do not always correlate with illness. Therefore antibodies may only reflect prior exposure, but do not necessarily document that Bartonella is the cause of the current disease.

Bartonella spp. infections in dogs are increasingly reported. Dogs show a variety of clinical manifestations ranging from asymptomatic to severe disease, a fact that makes clinical diagnosis quite difficult. Studies have shown that infection with B. vinsonii ssp. berkhoffii can induce polyarthritis, seizures, vasculitis, epistaxis and endocarditis in dogs (all of which occurred in progression in the illustrated case report).

Other underlying co-infections which are also vectorborne, such as infections with Ehrlichia canis and Babesia spp., may further influence the clinical presentation and also influence the prognosis, particularly if all co-infected organisms are not detected or specifically treated. Finally, laboratory diagnosis of Bartonella infection in dogs can also be quite difficult and time-consuming (if performed by culturing). Many of these aspects could be illustrated in this case report of a confusing tick-borne disease and should be kept in mind by veterinary clinicians.

\section{Competing interests}

Drs Breitschwerdt and Maggi are scientific officers for Galaxy Diagnostics, a newly formed company devoted to enhanced detection of Bartonella spp. infection in animals and human beings and located in Raleigh, NC, USA.

\section{Authors' contributions}

Drs Breitschwerdt and Maggi have collaborated for the past five years on studies to enhance the diagnosis, treatment and prevention of Bartonella infection in animals and human beings. Each contributed equally to the content of this case report. 


\section{Acknowledgements}

We thank the members of the Vector-Borne Diseases Diagnostic Laboratory and the Intracellular Pathogens Research Laboratory for providing the diagnostic and research expertise that facilitated the evaluation of this dog.

This article is published as part of Parasites \& Vectors Volume 2 Supplement I, 2009: Proceedings of the 4th International Canine Vector-Borne Disease Symposium. The full contents of the supplement are available online at http://www.parasitesandvectors.com/supplements/2/SI

Publication of the supplement has been sponsored by Bayer Animal Health $\mathrm{GmbH}$.

\section{References}

I. Breitschwerdt EB, Kordick DL, Malarkey DE, Keene B, Hadfield TL, Wilson K: Endocarditis in a dog due to infection with a novel Bartonella subspecies. J Clin Microbiol I995, 33:I54-I60.

2. Kordick DL, Swaminathan B, Greene CT, Wilson KH, O'Connor S, Hollis DG, Matar GM, Malcolm GB, Hayes PS, Hadfield TL, Breitschwerdt $E B$, Brenner DJ: Bartonella vinsonii subsp. berkhoffii subsp. nov., isolated from dogs; Bartonella vinsonii subsp. vinsonii; and emended description of Bartonella vinsonii. Int J Syst Bacteriol 1996, 46:704-709.

3. Breitschwerdt EB, Atkins CE, Brown TT, Kordick DL, Snyder PS: Bartonella vinsonii supsp. berkhoffii and related members of the alpha subdivision of the Proteobacteria in dogs with cardiac arrhythmias, endocarditis, or myocarditis. J Clin Microbiol 1999, 37:3618-3626.

4. Michau TM, Breitschwerdt EB, Gilger BC, Davidson MG: Bartonella vinsonii subspecies berkhoffii as a possible cause of anterior uveitis and choroiditis in a dog. Vet Ophthalmol 2003, 6:299-304.

5. Pappalardo BL, Brown T, Gookin JL, Morrill CL, Breitschwerdt EB Granulomatous disease associated with Bartonella infection in 2 dogs. J Vet Intern Med 2000, 14:37-42.

6. Pappalardo BL, Brown TT, Tompkins M, Breitschwerdt EB: Immunopathology of Bartonella vinsonii (berkhoffii) in experimentally infected dogs. Vet Immunol Immunopathol 200I, 83:125-147.

7. Duncan AW, Maggi RG, Breitschwerdt EB: A combined approach for the enhanced detection and isolation of Bartonella species in dog blood samples: pre-enrichment liquid culture followed by PCR and subculture onto agar plates. J Microbiol Methods 2007, 69:273-28I.

8. Duncan AW, Marr HS, Birkenheuer AJ, Maggi RG, Williams LE, Correa MT, Breitschwerdt EB: Bartonella DNA in the blood and lymph nodes of Golden Retrievers with lymphoma and in healthy controls. J Vet Intern Med 2008, 22:89-95.

9. Gillespie TN, Washabau RJ, Goldschmidt MH, Cullen JM, Rogala AR, Breitschwerdt EB: Detection of Bartonella henselae and Bartonella clarridgeiae DNA in hepatic specimens from two dogs with hepatic disease. J Am Vet Med Assoc 2003, 222:47-5I, 35.

10. Kitchell BE, Fan TM, Kordick D, Breitschwerdt EB, Wollenberg G Lichtensteiger CA: Peliosis hepatis in a dog infected with Bartonella henselae. J Am Vet Med Assoc 2000; 21 6:5 19-523, 517.

II. Saunders GK, Monroe WE: Systemic granulomatous disease and sialometaplasia in a dog with Bartonella infection. Vet Pathol 2006, 43:391-392.

12. Chomel BB, Mac Donald KA, Kasten RW, Chang CC, Wey AC, Foley JE, Thomas WP, Kittleson MD: Aortic valve endocarditis in a dog due to Bartonella clarridgeiae. J Clin Microbiol 200 I, 39:3548-3554.

13. Chomel BB, Wey AC, Kasten RW: Isolation of Bartonella washoensis from a dog with mitral valve endocarditis. J Clin Microbiol 2003, 4 I:5327-5332.

14. Boulouis HJ, Chang CC, Henn JB, Kasten RW, Chomel BB: Factors associated with the rapid emergence of zoonotic Bartonella infections. Vet Res 2005, 36:383-4I0.

15. Kelly P, Rolain JM, Maggi R, Sontakke S, Keene B, Hunter S, Lepidi H, Breitschwerdt KT, Breitschwerdt EB: Bartonella quintana endocarditis in dogs. Emerg Infect Dis 2006, I 2: I869-1872.

16. Billeter SA, Levy MG, Chomel BB, Breitschwerdt EB: Vector transmission of Bartonella species with emphasis on the potential for tick transmission. Med Vet Entomol 2008, 22: I- I5.
17. Cotté V, Bonnet S, Le Rhun D, Le Naour E, Chauvin A, Boulouis HJ, Lecuelle B, Lilin T, Vayssier-Taussat M: Transmission of Bartonella henselae by Ixodes ricinus. Emerg Infect Dis 2008, I 4:1074- 1080.

18. Pappalardo BL, Correa MT, York CC, Peat CY, Breitschwerdt EB: Epidemiologic evaluation of the risk factors associated with exposure and seroreactivity to Bartonella vinsonii in dogs. Am J Vet Res 1997, 58:467-47I. Risk factors for epidemiology.

19. Chang C-C, Kasten RW, Chomel BB, Simpson DC, Hew CM, Kordick DL, Heller R, Piemont Y, Breitschwerdt EB: Coyotes (Canis latrans) as the reservoir for a human pathogenic Bartonella sp.: molecular epidemiology of Bartonella vinsonii subsp. berkhoffii infection in coyotes from central coastal California. J Clin Microbiol 2000, 38:4193-4200.

20. Maggi RG, Chomel B, Hegarty BC, Henn J, Breitschwerdt EB: A Bartonella vinsonii berkhoffii typing scheme based upon I6S23S ITS and Pap3 I sequences from dog, coyote, gray fox, and human isolates. Mol Cell Probes 2006, 20:128-I34.

21. Smith BE, Tompkins MB, Breitschwerdt EB: Antinuclear antibodies can be detected in dog sera reactive to Bartonella vinsonii subsp. berkhoffii, Ehrlichia canis, or Leishmania infantum antigens. J Vet Intern Med 2004, I 8:47-5I.

22. Maggi RG, Duncan AW, Breitschwerdt EB: Novel chemically modified liquid medium that will support the growth of seven Bartonella species. J Clin Microbiol 2005, 43:265 I-2655.

23. Riess T, Dietrich F, Schmidt KV, Kaiser PO, Schwarz H, Schäfer A, Kempf VA: Analysis of a novel insect-cell culture mediumbased growth medium for Bartonella species. Appl Environ Microbiol 2008, 74:5224-5227.

24. Chomel BB, Boulouis HJ, Maruyama S, Breitschwerdt EB: Bartonella spp. in pets and effect on human health. Emerg Infect Dis 2006, 12:389-394.

25. Chomel BB, Kasten RW, Sykes JE, Boulouis HJ, Breitschwerdt EB: Clinical impact of persistent Bartonella bacteremia in humans and animals. Ann NY Acad Sci 2003, 990:267-278.

26. Mexas AM, Hancock SI, Breitschwerdt EB: Bartonella henselae and Bartonella elizabethae as potential canine pathogens. J Clin Microbiol 2002, 40:4670-4674.

27. Morales SC, Breitschwerdt EB, Washabau RJ, Matise I, Maggi RG, Duncan AW: Detection of Bartonella henselae DNA in two dogs with pyogranulomatous lymphadenitis. J Am Vet Med Assoc. 2007, 230:68I-685.

28. Goodman RA, Breitschwerdt EB: Clinicopathologic findings in dogs seroreactive to Bartonella henselae antigens. Am J Vet Res 2005, 66:2060-2064.

29. Diniz PP, Maggi RG, Schwartz DS, Cadenas MB, Bradley JM, Hegarty B, Breitschwerdt EB: Canine bartonellosis: serological and molecular prevalence in Brazil and evidence of co-infection with Bartonella henselae and Bartonella vinsonii subsp. berkhoffii. Vet Res 2007, 38:697-710.

30. Mellor PJ, Fetz K, Maggi RG, Haugland S, Dunning M, Villiers EJ, Mellanby RJ, Williams D, Breitschwerdt E, Herrtage ME: Alpha Iproteinase inhibitor deficiency and Bartonella infection in association with panniculitis, polyarthritis, and meningitis in a dog. J Vet Intern Med 2006, 20:1023-1028.

31. Breitschwerdt EB, Blann KR, Stebbins ME, Muñana KR, Davidson MG, jackson HA, Willard MD: Clinicopathologic abnormalities and treatment response in $\mathbf{2 4}$ dogs seroreactive to Bartonella vinsonii (berkhoffii) antigens. J Am Anim Hosp Assoc 2004, 40:92IOI. 